\title{
BIBECHANA
}

A Multidisciplinary Journal of Science, Technology and Mathematics

ISSN 2091-0762 (Print), 2382-5340 (0nline)

Journal homepage: http://nepjol.info/index.php/BIBECHANA

Publisher: Research Council of Science and Technology, Biratnagar, Nepal

\section{Density and partial molar volume of Sodium Dodecyl Sulfate in presence and absence of Sodium Sulfate and Zinc Sulfate in distilled water}

\author{
Kuber Limbu, Sujit Kumar Shah, Ajaya Bhattarai" \\ Department of Chemistry, M.M.A.M.C., Tribhuvan University, Biratnagar, Nepal \\ *E-mail: bkajaya@yahoo.com \\ Article history: Received 09 September, 2018; Accepted 27 October, 2018 \\ DOI: http://dx.doi.org/10.3126/bibechana.v16i0.21515 \\ This work is licensed under the Creative Commons CC BY-NC License. \\ https://creativecommons.org/licenses/by-nc/4.0/
}

\section{(c) (1) (8)}

\begin{abstract}
The precise measurements of density of sodium dodecyl sulfate (SDS) in distilled water and in presence of $0.01 \mathrm{M} \mathrm{Na}_{2} \mathrm{SO}_{4}$ and $0.01 \mathrm{M} \mathrm{ZnSO}_{4}$ at room temperature were measured by OstwaldSprengel type pycnometer. The density of SDS in distilled water was found lower than the density of SDS in $\mathrm{Na}_{2} \mathrm{SO}_{4}$ and $\mathrm{ZnSO}_{4}$ solutions whereas the density of SDS in the presence of $\mathrm{ZnSO}_{4}$ is higher than the density of SDS in the presence of $\mathrm{Na}_{2} \mathrm{SO}_{4}$. The partial molar volume of SDS in distilled water was obtained higher than in presence of $\mathrm{Na}_{2} \mathrm{SO}_{4}$ and $\mathrm{ZnSO} 4$ solutions.
\end{abstract}

Keywords: Sodiumdodecyl sulfate; $\mathrm{Na}_{2} \mathrm{SO}_{4} ; \mathrm{ZnSO}_{4}$.; Density; Partial molar volume(pmv).

\section{Introduction}

In Physical chemistry research, the density of surfactant solution is very important. It can be observed that the density of the system increases with the addition of surfactant [1]. Such behavior has been noticed for the density of surfactants in the various literature $[2,3]$. The density of surfactant solutions is used to calculate the critical micelle concentration $[4,5,6]$ and the partial molar volume [1]. The partial molar volume is the thermodynamic quantity of the surfactant and is very useful to elucidating the interactions occurring in solutions and to examine the behaviours of surfactant solutions [7]. Particularly, detailed definitions and explanations of the partial molar volume have been provided in several papers $[8,9]$. The density and partial molar volume, $\bar{V}$, is defined by the following equation[10];

$$
\bar{V}=(\partial V / \partial n)_{T, p}
$$

where, $\partial V$ represent change in total volume and $\mathrm{n}$ as the number of moles. The partial molar volume is often provided in units of partial molar volume $\mathrm{cm} 3 / \mathrm{mol}$. The concentration dependence of the 
partial molar volume is accounted by using the following equation which calculate the apparent molar volume at the finite concentrations $\mathrm{c}[8]$.

$$
\bar{V}=\frac{M}{\rho_{0}}-\frac{10^{3}}{c}\left(\frac{\rho}{\rho_{0}}-1\right)
$$

where, $\mathrm{M}$ is the molecular weight of the SDS , $\rho_{0}$ is the density of the solvent, $\rho$ is the density of the solution and $\mathrm{c}$ is having the unit as equivalent concentration in $\mathrm{mol} / \mathrm{L}$.

Our aim is to determine of densities and pmv of different solutions of SDS and their comparison with the solutions of SDS in the presence of salts.

\section{Experimental}

Sodium dodecyl sulfate (SDS) of molecular weight $288.38 \mathrm{~g} / \mathrm{mol}$ was purchased from Merck Specialities Pvt. Ltd., Mumbai, India whereas sodium sulfate and zinc sulfate was purchased from Ranbaxy Pvt. Ltd., Mumbai, India. Single distilled water was used as primary solvents for the preparation of different experimental solutions of different concentrations of SDS in absence and presence of sodium sulfate and zinc sulfate.

Electronic balance was used for weighing the different concentrations of SDS, sodium sulfate and zinc sulfate. Ostwald-Sprengel type pycnometer was used to measure density. For this purpose, the cleaned Ostwald-Sprengel type pycnometer was taken and was first filled with air-free distilled water in it, then the stopper was inserted into its mouth so that the small amount of water flowed out the capillary then the outer surface of it was wiped out with a tissue paper ensuring that outer surface was completely dried. Finally the Ostwald-Sprengel type pycnometer was weighed and then contents after allowing them to stand for a short time. The Ostwald-Sprengel type pycnometer was then emptied and dried. Then the same process was repeated for every type of solutions under investigations. After collecting the weights, densities of related solutions were calculated and tabulated with reference to the standard density of water at $30 \mathrm{oC}$ i.e. $0.99571 \mathrm{~g} / \mathrm{cm} 3$. The pmv values were also calculated and tabulated along with densities.

The calculated densities and pmv values of SDS in aqueous and in presence of salts with different concentrations were plotted in the graph with the help of Easy Plot Software.

\section{Results and Discussion}

The densities of SDS in distilled water, $\mathrm{Na} 2 \mathrm{SO} 4$ and $\mathrm{ZnSO} 4$ solution have been calculated and compared with a wide range of concentrations of SDS (Table 1). Density has been found to be increased significantly on going from distilled water to $\mathrm{Na} 2 \mathrm{SO} 4$ and $\mathrm{ZnSO} 4$. The density increased with the increase of molecular weight of the added salts. In our case the molecular weight of sodium sulfate is $142.04 \mathrm{~g} / \mathrm{mol}$ whereas for zinc sulfate is $161.47 \mathrm{~g} / \mathrm{mol}$. So, the density of SDS in the presence of zinc sulfate is high than the density of SDS in the presence of sodium sulfate (Figure 1). It is not possible to calculate the critical micelle concentration of SDS in distilled water and in the presence of salts because the investigated concentrations of SDS in higher concentration are in regular trends whereas the lower concentration below the critical micelle concentration is in irregular trends and hence there will not possible to see the accurate intersection point between the pre and post micellar slope of the surfactant solutions. This is may be due to the presence of the impurities and the fluctuations of the temperature while measuring the density of the solutions. 
The calculation of the partial molar volume of SDS in distilled water and in presence of salts is the good option to see the solute and solvent interactions. Partial molar volume (pmv) of SDS has been found to be higher in distilled water and gradually decreased in other salts (Table 2 and Figure 2).

Table 1: Density of SDS in distilled water, $\mathrm{Na}_{2} \mathrm{SO}_{4}$ and $\mathrm{ZnSO}_{4}$ at $30^{\circ} \mathrm{C}$.

\begin{tabular}{|c|c|c|}
\hline Solvent & Concentration $(\mathrm{mol} / \mathrm{Lt})$ & Density $\left(\mathrm{g} / \mathrm{cm}^{-3}\right)$ \\
\hline Pure distilled water & $\begin{array}{l}0.100076 \\
0.080061 \\
0.060046 \\
0.04003 \\
0.024018 \\
0.018014 \\
0.012009 \\
0.007205 \\
0.005404\end{array}$ & $\begin{array}{l}0.999567 \\
0.997363 \\
0.996733 \\
0.996064 \\
0.995749 \\
0.995671 \\
0.995395 \\
0.995316 \\
0.995238\end{array}$ \\
\hline $\mathrm{Na}_{2} \mathrm{SO}_{4}$ & $\begin{array}{l}0.10008 \\
0.080061 \\
0.060046 \\
0.04003 \\
0.024018 \\
0.018014 \\
0.012009 \\
0.007205 \\
0.005404\end{array}$ & $\begin{array}{l}1.000000 \\
0.999685 \\
0.999056 \\
0.99819 \\
0.997678 \\
0.997599 \\
0.997284 \\
0.997166 \\
0.997088\end{array}$ \\
\hline $\mathrm{ZnSO}_{4}$ & $\begin{array}{l}0.100284 \\
0.080227 \\
0.060171 \\
0.040114 \\
0.024007 \\
0.018051 \\
0.012034 \\
0.00722 \\
0.005415\end{array}$ & $\begin{array}{l}1.000788 \\
0.999922 \\
0.999213 \\
0.998426 \\
0.997757 \\
0.997678 \\
0.997481 \\
0.997363 \\
0.997206\end{array}$ \\
\hline
\end{tabular}


Kuber Limbu et al. / BIBECHANA 16 (2019) 131-136: RCOST p.134 (Online Publication: Dec., 2018)

Table2: Partial molar volume of SDS in distilled water, $\mathrm{Na}_{2} \mathrm{SO}_{4}$ and $\mathrm{ZnSO}_{4}$ at $30^{\circ} \mathrm{C}$.

\begin{tabular}{|c|c|c|}
\hline Solvents & Concentration $(\mathrm{mol} / \mathrm{Lt})$ & $\mathrm{pmv}\left(\mathrm{cm}^{3} / \mathrm{mol}\right)$ \\
\hline Distilled water & $\begin{array}{l}0.100076 \\
0.080061 \\
0.060046 \\
0.04003 \\
0.024018 \\
0.018014 \\
0.012009 \\
0.007205 \\
0.005404\end{array}$ & $\begin{array}{l}250.9122 \\
268.8848 \\
272.5057 \\
280.7349 \\
287.9766 \\
291.8169 \\
315.956 \\
344.4908 \\
377.4008\end{array}$ \\
\hline $\mathrm{Na}_{2} \mathrm{SO}_{4}$ & $\begin{array}{l}0.10008 \\
0.080061 \\
0.060046 \\
0.04003 \\
0.024018 \\
0.018014 \\
0.012009 \\
0.007205 \\
0.005404\end{array}$ & $\begin{array}{l}251.1895 \\
245.562 \\
241.4493 \\
239.146 \\
226.9728 \\
210.5221 \\
197.3616 \\
152.3965 \\
121.3232\end{array}$ \\
\hline$\overline{\mathrm{ZnSO}_{4}}$ & $\begin{array}{l}0.100284 \\
0.080227 \\
0.060171 \\
0.040114 \\
0.024007 \\
0.018051 \\
0.012034 \\
0.00722 \\
0.005415\end{array}$ & $\begin{array}{l}251.0638 \\
252.3419 \\
251.8475 \\
252.8272 \\
256.3429 \\
249.8579 \\
246.562 \\
234.5024 \\
245.4129\end{array}$ \\
\hline
\end{tabular}


Kuber Limbu et al. / BIBECHANA 16 (2019) 131-136: RCOST p.135 (Online Publication: Dec., 2018)

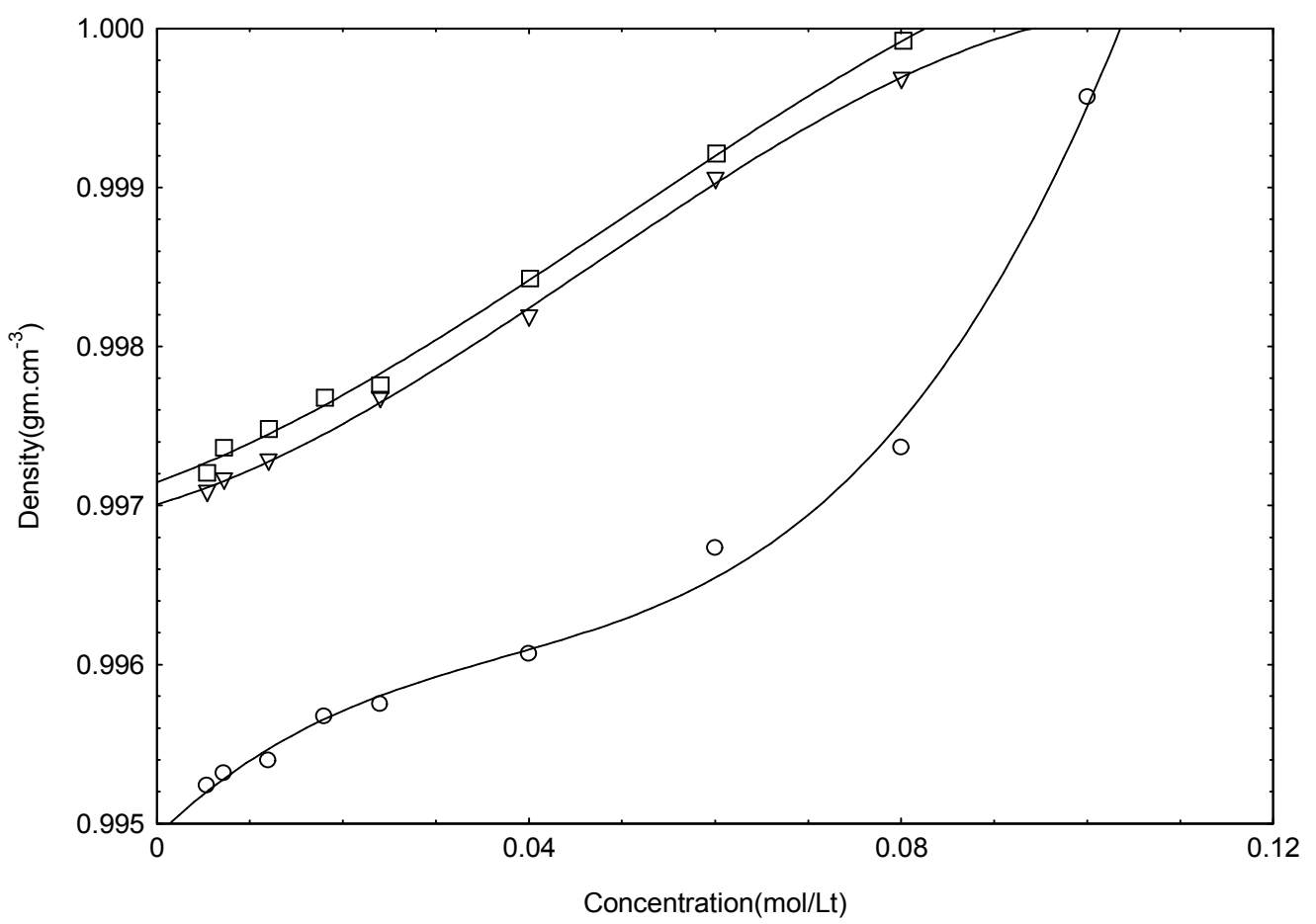

Fig.1: Density of SDS in distilled water (circles), $\mathrm{Na}_{2} \mathrm{SO}_{4}$ (opposite triangles) and $\mathrm{ZnSO}_{4}$ (squares).

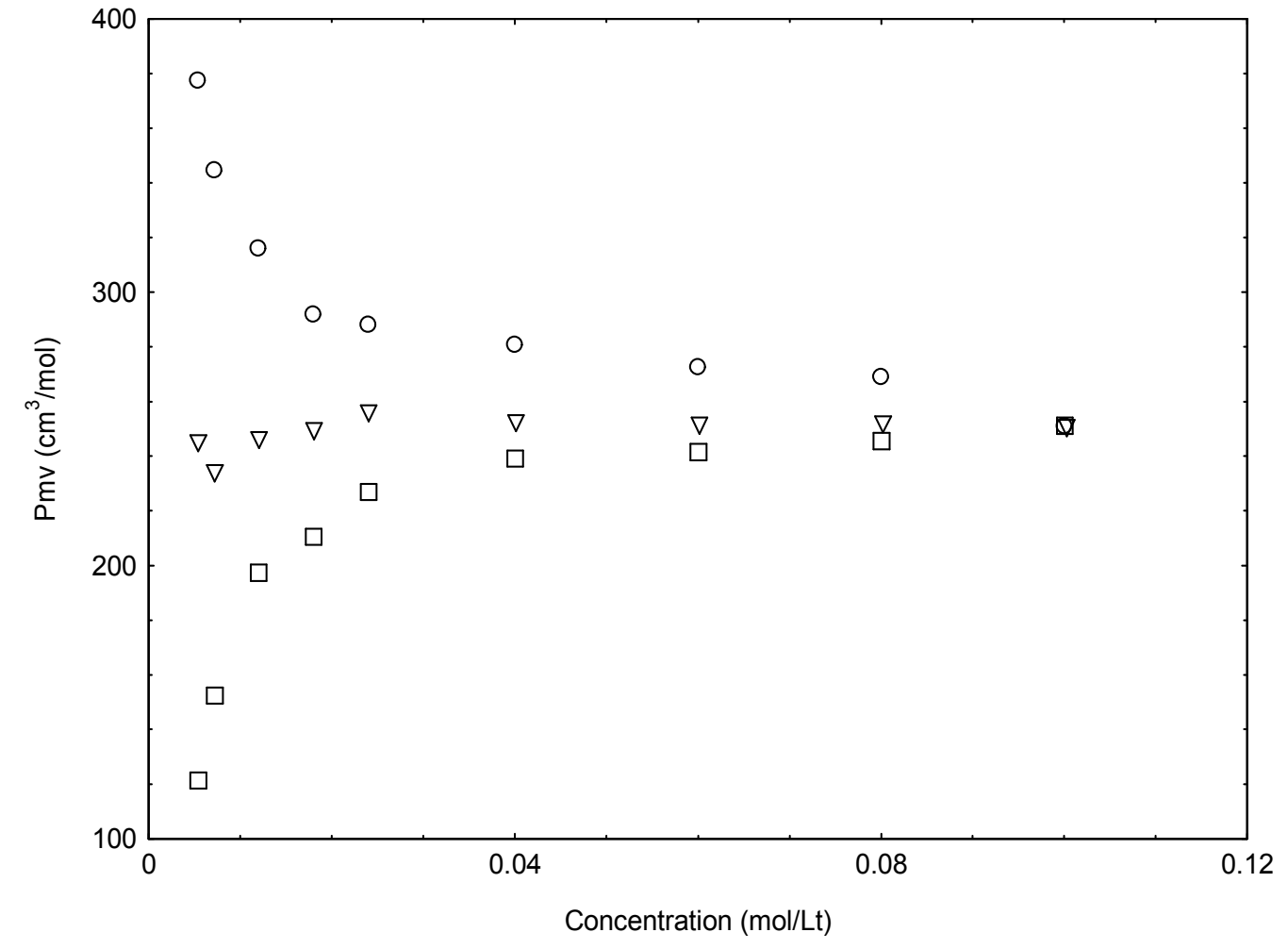

Fig. 2: Partial molar volumes of SDS in distilled water (circles), $\mathrm{ZnSO}_{4}$ (opposite triangles) and $\mathrm{Na}_{2} \mathrm{SO}_{4}$ (squares). 


\section{Conclusion}

The following conclusion has been drawn from the above results and discussion. The density of SDS in distilled water is found to be low as compared to SDS solution in the presence of $\mathrm{Na}_{2} \mathrm{SO}_{4}$ and $\mathrm{ZnSO}_{4}$. The molecular weight of the substance is related with the density. The molecular weight of $\mathrm{ZnSO}_{4}$ is higher than the molecular weight of $\mathrm{Na}_{2} \mathrm{SO}_{4}$. Hence the density of SDS in the presence of $\mathrm{ZnSO}_{4}$ is higher than the density of SDS in the presence of $\mathrm{Na}_{2} \mathrm{SO}_{4}$. The values of the partial molar volumes are found to be higher of SDS in distilled water in comparison with the values of the partial molar volumes of SDS in the presence of $\mathrm{Na}_{2} \mathrm{SO}_{4}$ and $\mathrm{ZnSO}_{4}$.

\section{Acknowledgments}

One of the authors (Kuber Limbu) is thankful to the University Grants Commission (UGC), Nepal, for providing grants for M. Sc.Dissertation work. Authors are also grateful to Associate Professor Ghanashyam Shrivastav, Head of Department of Chemistry, M.M.A.M.C., Biratnagar, Nepal for providing the available research facilities to conduct this research work.

\section{References}

[1] A. Bhattarai, S.K. Chatterjee, T. K. Deo, T. P. Niraula, Effects of concentration, temperature, and solvent composition on the partial molar volumes of sodium lauryl sulfate in methanol (1) + water (2) mixed solvent media, J. Chem. Eng. Data, 56(2011) 3400-3405. https://pubs.acs.org/doi/abs/10.1021/je2003622.

[2] S. K. Thakur, S.Chauhan, Ultrasonic velocity and allied parameters of drug colimax in aqueous 1propanol at 298.15 K, J. Chem. Pharm. Res. 3 (2011) 657-664. http://www.jocpr.com/articles/ultrasonicvelocity-and-allied-parameters-of-drug-colimax-in-aqueous-1 propanol-at-29815k.pdf.

[3] V. K. Syal, S. K. Thakur, S. Chauhan, P. Sharma, Ultrasonic velocity studies of drug parvon-spas in mixed alcohol-water solvent systems at 298.15 K, Int. J. Thermophys. 26 (2005) 807-826. https://link.springer.com/article/10.1007/s10765-005-5579-1.

[4] B. Farhadieh, Determination of CMC and partial specific volume of polysorbates 20, 60, and 80 from densities of their aqueous solutions, J. Pharm. Sci. 62(1973), 1685-1688.

https://www.ncbi.nlm.nih.gov/pubmed/4752114.

[5] A. Bhattarai, C. N. Adhikari, G.S. Shrivastav, Density and partial molar volume of cetyltrimethylammonium bromide in the presence and absence of Na2SO4 and MgSO4, Int. J. Eng. \& Tech. Res. 2(11) (2014)74-76. www.erpublication.org.

[6] A. Bhattarai, S. K. Chatterjee, K. Jha, Density and partial molar volume of cetyltrimethylammonium bromide in the presence and absence of $\mathrm{KCl}$ and $\mathrm{NaCl}$ in aqueous media at room temperature, Physical Chemistry 5(1) (2015) 1-5. http://article.sapub.org/10.5923.j.pc.20150501.01.html.

[7] M. F. Hossain, T. K. Biswas, M. N. Islam, M. E. Huque, Volumetric and viscometric studies on dodecyltrimethylammonium bromide in aqueous and in aqueous amino acid solutions in premicellar region, Monatsh Chem. 141 (2010) 1297-1308. https://link.springer.com/article/10.1007/s00706-0100402-5.

[8] H. Eisenberg, 1976. In Biological Macromolecules and polyelectrolytes in Solution Clarendron, Oxford.

[9] H. Durchschlag, P. Zipper, Calculation of the partial volume of organic compounds and polymers, Prog. Colloid Polym. Sci. 94(1994)20-39. https://link.springer.com/chapter/10.1007/BFb0115599.

[10] C. Wandrey, A. Bartkowiak, D. Hunkeler, Partial Molar and Specific Volumes of Polyelectrolytes: Comparison of Experimental and Predicted Values in Salt-free Solutions, Langmuir 15 (1999) 40624068. https://pubs.acs.org/doi/abs/10.1021/la981089d. 